\title{
Development of a Shotcrete Training Simulator for Civil Works
}

\section{Julián Estévez ${ }^{1 *}$, Angel Suescun ${ }^{2}$, Gorka Velez $^{3}$, and Fernando Ordás ${ }^{4}$}

${ }^{1}$ Department of Mechanical Engineering, University of the Basque Country, Spain

${ }^{2}$ Universidad de Navarra, Tecnun, Spain

${ }^{3}$ Vicomtech, Spain

${ }^{4}$ Fundación Santa Barbara, Spain

\begin{abstract}
Santa Barbara Foundation Labour School decided to develop a training simulator for the teaching of the shotcrete process before the practice with the machine. Thanks to this, students will have a wider experience when using the real machine.

This paper describes the criteria of interactivity, realism, and exercises evaluation and indicators in order to fulfil efficiently the requirements of shotcrete machine teaching. Once the simulator is developed, a different survey is made to a group of volunteers that were trained with it in order to validate the shotcrete machine simulator as a learning tool.

The findings of this work consist in introducing the development criteria for the design of a shotcrete training simulator. These decisions were made by researchers and mining school teachers of Santa Barbara Foundation Labour School taking into account the safety and special conditions of this kind of construction works and the state of art and reviews of other existing construction training simulators.
\end{abstract}

\section{Keywords}

Simulator, Learning, PBL, Evaluation

\section{Introduction}

Santa Barbara Foundation is a professional college specialized in vocational training courses and in continuous formation in following areas: Civil Works, Electromechanics, Renewable Energy and Welding. Teachers have a deep knowledge of those areas and the facilities permit offering a very practical teaching, even with real-scale civil works fo- cused on a good learning and professional specialization.

Santa Barbara Foundation (SBF) has recently initiated the teaching of shotcrete machines with the usage of training simulators. The college has imparted a wide variety of courses in heavy-machinery for years. There are several types of shotcrete machines. However, the specific one for this course

*Corresponding author: Julián Estévez, Department of Mechanical Engineering, University of the Basque Country, Donostia, Spain

Accepted: August 21, 2019; Published: August 23, 2019

Copyright: (C) 2019 Estévez J, et al. This is an open-access article distributed under the terms of the Creative Commons Attribution License, which permits unrestricted use, distribution, and reproduction in any medium, provided the original author and source are credited.

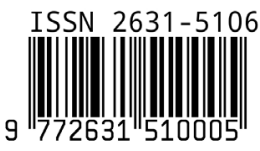

Estévez et al. Int J Robot Eng 2019, 4:015 
will be useful for the construction of tunnels, and its spraying is controlled by a robot arm. Real shotcrete machine usage in early stages of the course was discarded due to a series of disadvantages. First, lack of safety as a consequence of the inexperience. Second, the shotcrete is a very expensive resource, including costs of fuel, electricity, maintenance, shotcrete, additives and instructors salary. Finally, realistic tasks with the machine involve are characterised for loud noise and low visibility, which makes a good teaching almost impossible. In order to overcome these disadvantages, SBF proposed the usage of a training simulator (TS) as an early stage learning tool. Pupils start their formation on the simulator while they learn the machine procedure, management and shotcrete operation.

Taking into account this objective, the simulator was designed so that the users could interact with the controls of the shotcrete machine, prepare the shotcrete and manage breakdowns and failures along the activity. Formation is structured in progressive exercises that help evaluate the progress of pupils with objective criteria and instructor's subjective opinions. The purpose of present work is to describe the selected parameters and design of the TS for the teaching of a construction sector activity, and the correspondent validation. Previous review and critics made to this kind of tools were taken into account.

A state of the art review of TS in construction is presented in Section 4. In Section 5 of the present article, the shotcrete machine is described as well as the experience of SBF on simulation tools use on their learning courses. In Section 6, grade of realism of the simulator and its consequences in the learning process are detailed. Besides, TS hardware and software architecture are presented. Next, in Section 7, the different skills that must be acquired by pupils and what learning methodologies have been chosen for that are described. Besides, exercises that can be practised on the TS and how pupils will be evaluated is presented. In Section 8 , TS validation process is explained. Finally, in Section 9, efficiency of the TS as a proper learning tool for the shotcrete machine process is discussed.

\section{State of Art}

The usage of training simulators in workers of various kinds of jobs is common. For instance, they have shown to be effective in road-safety train- ing [1]. and in surgical procedures [2]. Virtual Reality (VR) systems offer the opportunity to expose workers to hazardous and unexpected situations, which forces the operator to implement an action and learn from the results. This results in cognitive information processing, which improves its longterm learning of this piece of knowledge [3]. However, the construction industry tends to lag behind other industries in terms of taking advantage of new technologies and innovative practices, and the use of immersive virtual reality for training interventions in construction to date is rare [4].

The current state of education in construction management is heavily based on traditional class teaching, which is not learning-centered neither 'experiential' learning thus inhibiting the use of educational methods that stimulate student learning $[5,6]$.

Moreover, initiatives of implementing VR environment for construction industry have often been criticised for simulating the construction processes on the assumption that all circumstances are optimal; that is, there are no external interruptions (such as human failures), assuming ideal working conditions. which could adversely impact the progress [7].

Different approaches have been studied for construction simulators in the last years. Goulding proposed a simulator for a building environment, in which work was developed through different interfaces that reproduced the different decision moments and data available for construction professionals [6]. Its main characteristic was the experiential-learning strategy, based on the different feedback from industry and academia. As an alternative, Sacks presented a construction simulator for building management too, but emphasized and validated the effectiveness of VR for the purpose of safety training in this sector [4].

Even it is designed for a chemical process industry, Manca presented the usefulness of introducing unexpected and hazardous situations in the training simulator for the operators teaching [8]. They defend that this strategy is valid for safety-critical sectors, such as oil, gas and industry, which all use heavy equipment. Finally, Alm and Valero use a validation method for a training simulator based on a series of subjective questions asked to voluntary operators. Alm develops this research for a shotcrete TS, while 
Valero uses a tunneling Jumbo TS $[9,10]$.

[11] Resumes the state of art of shotcrete machines and he classifies this apparatus in three types, depending on its spraying: Spraying by hand, by manipulator or by robot. Spraying by hand permits he worker to limit the quantity of concrete that can be handled, by controlling the nozzle and wielding tube. The technique of application has to be learned and requires a lot of experience.

Spraying by manipulator includes a conveying pump with a larger capacity which is controlled by the worker. This type permits a faster shotcrete process. However it still requires a big human experience. Finally, shotcrete by robot implies the manipulation of the nozzle with a robot which is mounted on the shotcrete vehicle, and helps for a better quality and spraying process with less experience.

\section{Description of the Shotcrete Machine and Formation Requirements}

The TS replicates a commercial shotcrete machine model, which is the model SBF works with (Figure 1). The simulator has been developed by CEIT together with SBF staff. CEIT keeps a wide experience in TS development: Jumbo tunnel-machine [10,12], undergrounds and railways [13], different cranes [14], etc. These apparatus are mainly employed in the building of tunnels and batter maintenance. The specific shotcrete machine is composed of a robotic arm of 7 dofs (degrees of freedom) whose mission is to orient and positionate the hose located at the end of the arm. This hose sprays the shotcrete. Machine starting is con- trolled with the panel Figure 1a. Different dofs of the robot are dominated by the remote control (Figure 1b).

Workers on the course of shotcrete machine training must learn following skills and abilities:

- Starting: Connect the electric engine, start the diesel engine, level the crane with the hydraulic jacks and prepare the shotcrete.

- Dofs control and management: Know the pump for the shotcrete, robotic arm movements for shotcrete hose orientation.

- Shotcrete techniques: Know different spraying strategies for an efficient job, depending on the type of surface and material of the tunnel or batters.

- Diagnose the breakdowns and correspondent know the procedure protocols.

The objective of the simulator is to provide the students of a tool to improve the learning process thanks to a series of specially designed exercises, automated feedback and the possibility to explore themselves the shotcrete machine and process. The TS is only used in the shotcrete machine early stages learning process. Once this process is completed, students have the possibility to make hands-on practice on real machine and experiment real working conditions, including visibility aspects.

\section{The Simulator}

\section{Hardware and software}

SBF equipped the classroom with eleven training simulators. These units are called Formation

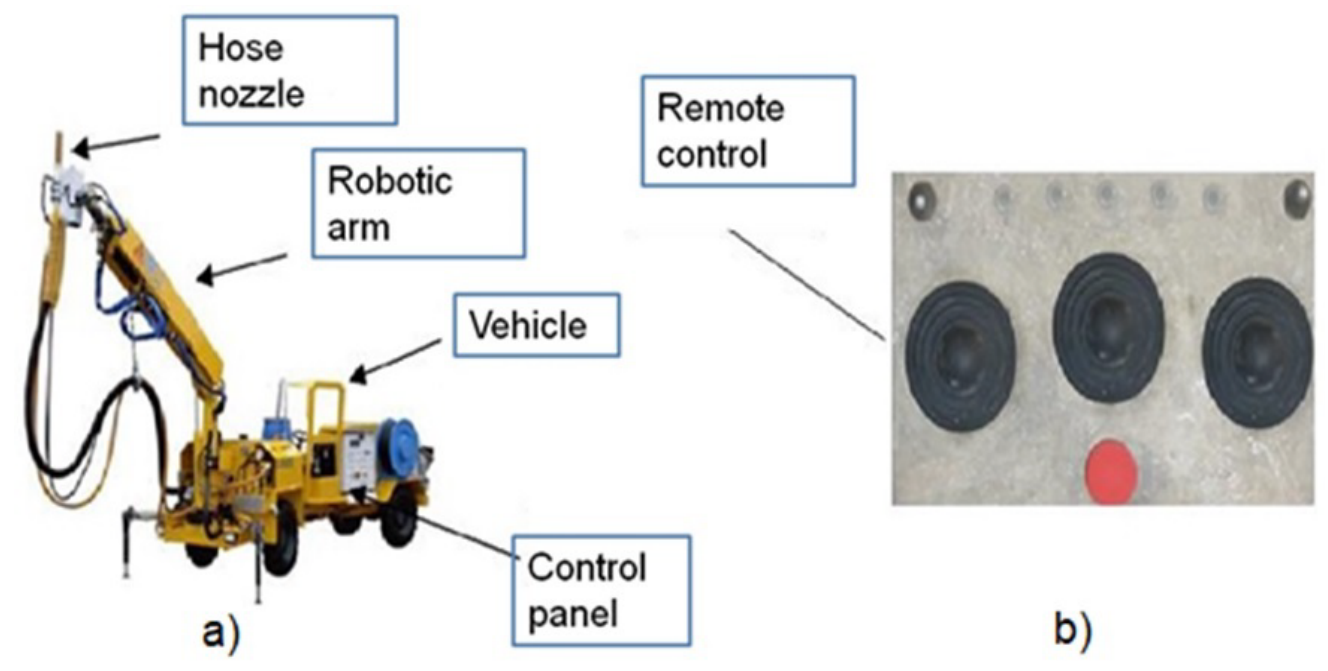

Figure 1: Shotcrete machine and remote control. 


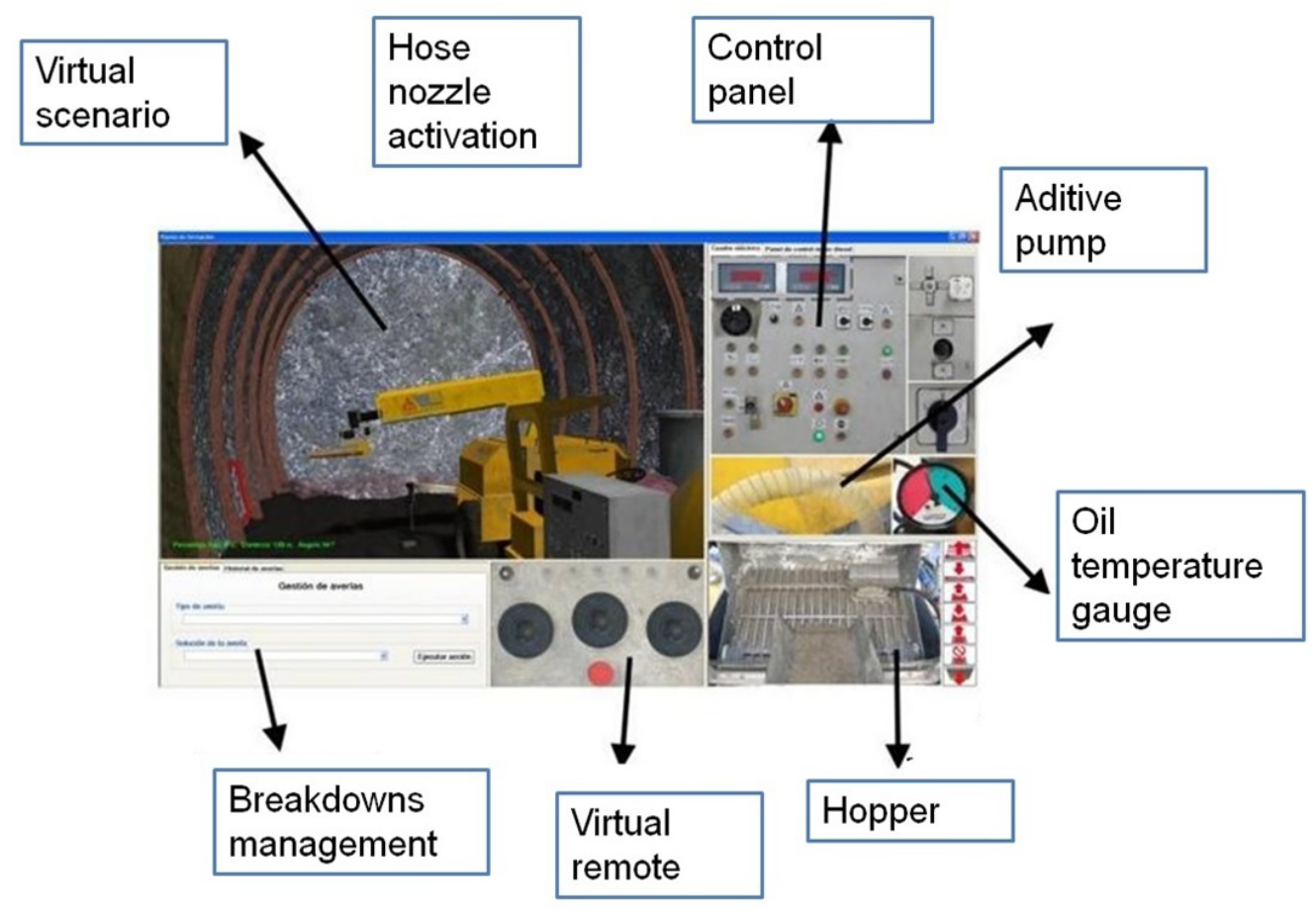

Figure 2: Formation post.

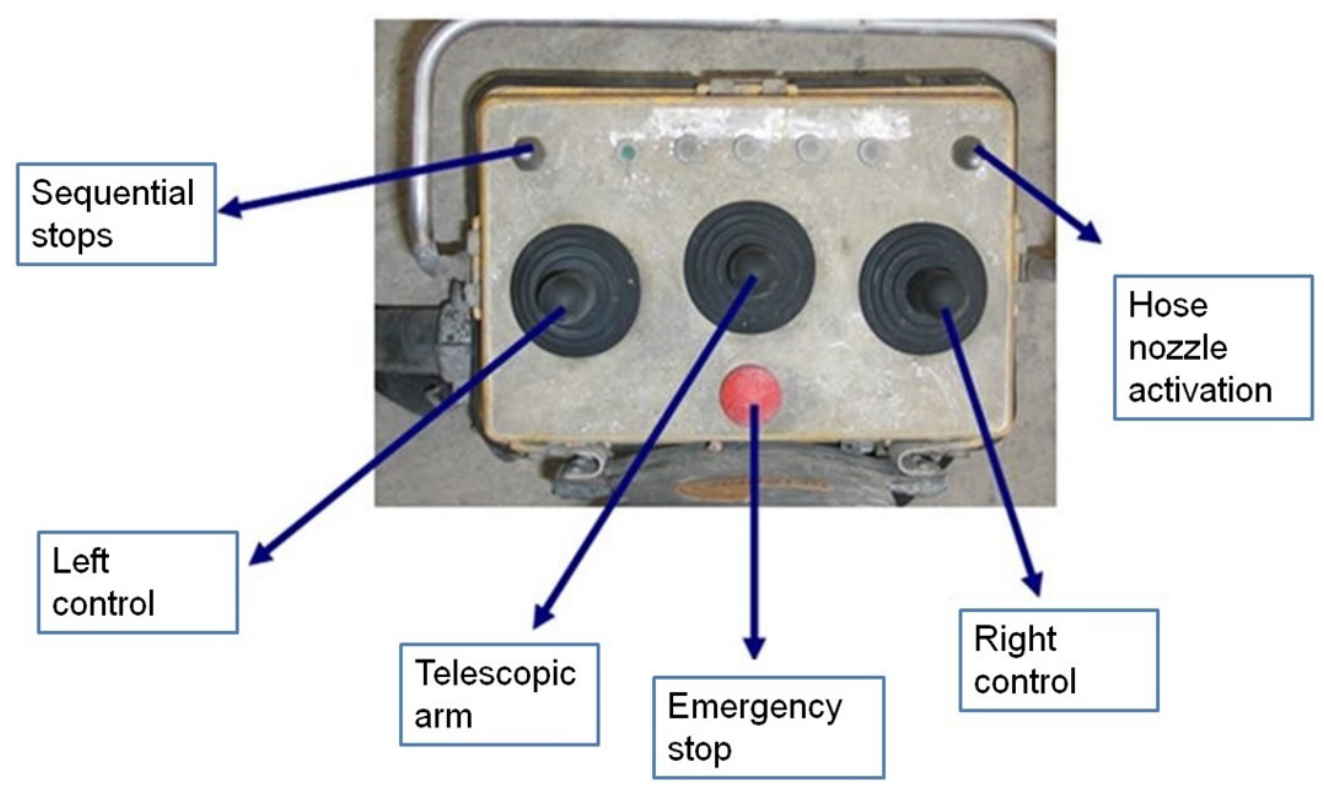

Figure 3: Real shotcrete machine remote.

Posts. At the same time, there is a twelfth computer, the Instructor Post, from where activities on the Formation Posts can be supervised. The functions of the instructor consist in the assignment of different exercises and online supervision of the pupils during them thanks to a remote desktop system. Formation Posts appear on Figure 2, while Figure 3 represents the remotes of the real shotcrete and of the TS (left and right, respectively). On Figure 4 a schematic image of the Instructor Post can be seen.
On the right, the instructor can choose which pupil to supervise thanks to a list of working stations (Formation Post 1 to 11) and configure the exercise. On the top, name of the pupil and the exercise that he is performing is shown, together with the possibility to program breakdowns on real-time. On the left, it can be seen the same dashboard that the student sees.

Hardware details and programming language is 

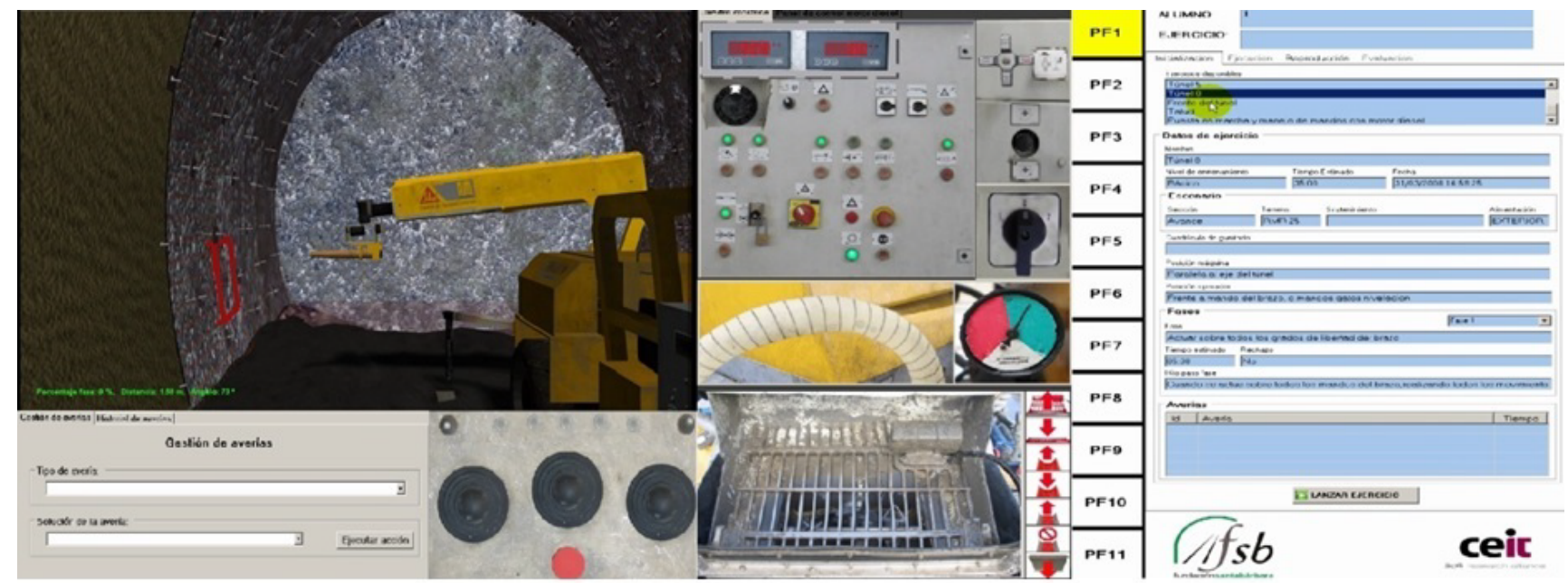

Figure 4: Instructor's post.

detailed in [15].

\section{User interface system}

On the Formation Post, interaction is achieved with the mouse. This device controls the virtual shotcrete dashboard, hopper and breakdowns management menu (see Figure 2). The robotic arm during the exercise is controlled with the remote (Figure 3). Virtual learning environment helps increasing the interactivity with characteristics that non-conventional learning does not offer [16].

\section{Realism}

It was generally accepted until that realism and high-fidelity simulators enhance the learning process, motivate the students and help them acquiring the trained skills in a more efficient way [17-19]. However, in the last few years, after highperformance computers turned usual, different researches are starting to diverge on the need of high-fidelity simulators and its direct relationship with the learning process. [20-22] prove that that participants in low-fidelity simulators outperform the high-fidelity students in the learning process. However, in the case of present work, tunnel and undercave conditions are involved, whose simulation conditions are very particular [23].

The simulator replicates realistically all the movements, management and visual features of the real shotcrete machine, which proved to enhance learning process in underground training simulators [24]. Besides, the simulator graphics are on 3D, so that immersion sensation improves the learning [25]. The visual system of the TS represents with high fidelity the machine and working conditions. It uses a graphic and physics model of the shotcrete spray and adherence developed by [15], whose main function is to enhance realism and shotcrete visualization.

However, it was decided not to replicate the low visibility conditions of the real work environment, which is full of dust and smoke. Authors of this article believe that this kind of realism distracts and decreases the learning capacities of the simulator exercises, as it was demonstrated in previous studies [24]. On the contrary, shotcrete machine characteristic noises have been realistically replicated, as they permit the early detection of some failures and incidences, and SBF decided to get used to pupils to that noise. Research works agree with the usage of noises in the learning process in simulators [26].

\section{Description of the Formation Strategy with the Simulator}

TS users will acquire different abilities focusing on the learning from Problem-Based-Learning methodology (PBL). PBL is the learning method that results from directing the learning process towards a problem comprehension and resolution. In order to enhance this system, the TS offers real tasks for an effective learning and an exploratory attitude of the students [27]. Besides, it has been proved that $\mathrm{PBL}$ increases the motivation and decreases the stress [28].

It is generally accepted that the incorporation of computers as a teaching tool enhances the learning process and some authors studied the effect 
Table 1: Start up and robotic arm exercises.

\section{Exercise type}

Start up and robot arm positioning

\section{Description}

Start up of the shotcrete machine

Concrete preparation and mixture

Usage of all the dofs of the robotic arm

Robotic arm proper positioning

Table 2: Tunnel and batter exercises.

\begin{tabular}{|c|c|c|}
\hline \multicolumn{2}{|l|}{ Exercise type } & Description \\
\hline \multirow{5}{*}{ Shotcrete exercises } & \multirow{3}{*}{ On tunnel } & Seal of the front (section of $5 \mathrm{~cm}$ thickness) \\
\hline & & Shotcrete over mesh and bolts \\
\hline & & Shotcrete over truss \\
\hline & \multirow{2}{*}{ On batter } & Seal of the front (section of $5 \mathrm{~cm}$ thickness) \\
\hline & & Shotcrete over special bolts \\
\hline
\end{tabular}

of PBL methodology in TS and check the positive effects $[18,19]$. The PBL implementation constrains the whole learning process through its main three characteristics:

- Problems as a stimulus for learning

- Tutors as facilitators

- Group work as stimulus for interaction

One of the PBL effects derived from the first principle is milestones implementation (Subsection 5.2), which have a big acceptance among PBL experiment participants and enhance the learning process $[29,30]$. Milestones turn the exercises structured so that superior level is based on the skills and concepts of a previous lower level plus a series of some new ideas. This technique is called scaffolding learning, which permits simple learning structures and focus on important tasks and sequences that pupils must acquire. Scaffolding learning is very important in PBL and eases the learning process: It helps students creating doubts and thus, increasing the exploratory attitude towards the problem resolution [28]. Besides, scaffolding learning permits the minimization of the instructions along the exercises of the TS. The decision of where to set the milestones to divide scaffold levels are taken by an experimented shotcrete process tutor.

About the third PBL principle, work group, all the TS exercises are developed in a classroom, where students can talk among them even although each one uses a single simulator and is responsible for his exercise. This freedom tries to resemble the real working conditions of the shot- crete process and keeps the students motivation higher. Second PBL characteristic is explained in Subsection 6.4.

\section{Formation plan description}

As a result of the methodology described in Section 6, the TS offers two kind of exercises:

1. Start up of the machine and robotic arm positioning (Table 1 )

\section{Shotcrete on tunnel and batter (Table 2)}

Exercise type no. 2 also requires start up and positioning of the robotic arm. Milestones in exercises are time limited. Shotcreted surface percentage, layer thickness and uniformity are evaluated. Along the exercises, different types of working and shotcrete failures can happen. The TS considers the exercise completed when it detects all the programmed milestones.

Formation plan is composed of three levels. When advancing the level, the hardness of exercises is augmented by increasing the quantity of shotcrete to spray, or varying heights of the tunnel and limit time, and changing the kind of breakdowns and failures. No exercise can be overcome till all the breakdowns are managed.

The duration of the training is organized as follows: Each day takes 2 hours of training approximately. First day is used for the first contact with the shotcrete simulator and the fulfilment of exercises in Table 1. Second and third days are used for the completion of tunnel exercises in Table 2 . Fourth and fifth days are booked for batter exercis- 


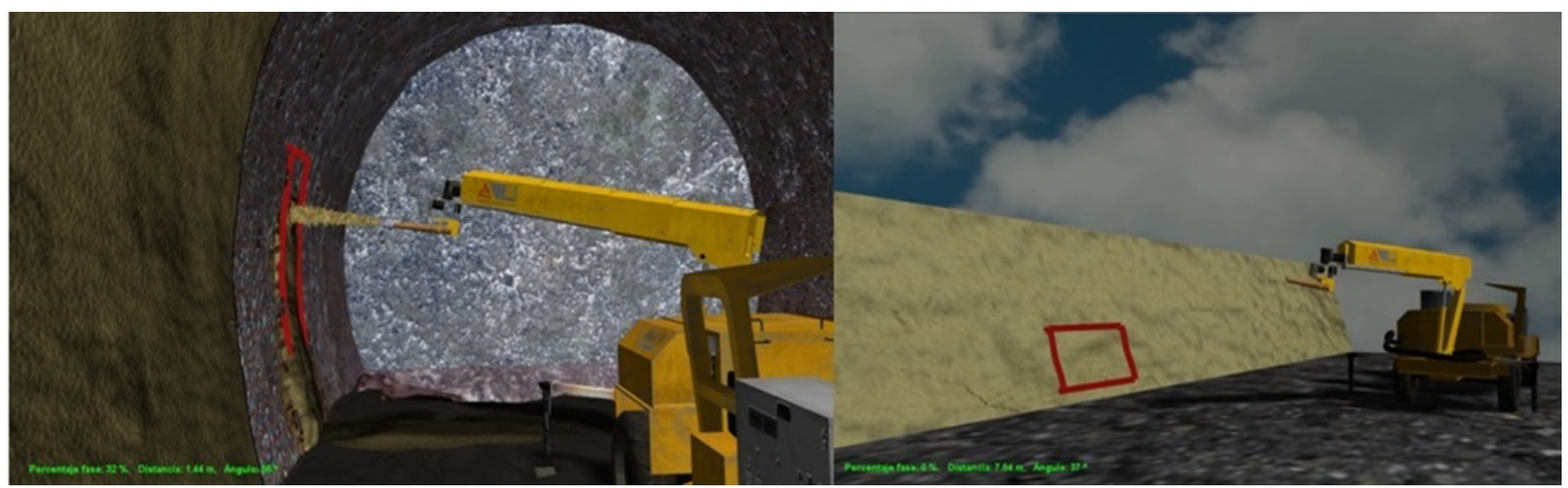

Figure 5: Red square region.

es in the same Table 2.

\section{Formation content}

Students are trained in following type of skills:

- Cognitive skills: Shotcrete machine working process, its operation and shotcrete spraying process. SBF teaches these skills of theoretic classes with are complemented with the simulator training sessions.

- Perceptual skills: The simulator replicates the breakdowns, noises and incidence that the real shotcrete machine can suffer, and counts on a graphic and physics realistic shotcrete model. All this permits the pupil to obtain info from the environment, and act on the shotcrete machine according to different situations.

- Motor skills: Pupils train on the usage and control of a remote which is equivalent to the real shotcrete machine one.

\section{Pupils aid options}

Once first milestones are overcome (machine start up and robotic arm positioning), the simulator user starts seeing the surface to spray the shotcrete marked with a red square area. The student can see the percentage of shotcreted area and when finished, the simulator will automatically mark the next area to spray according to a logical order for that civil work (Figure 5).

From the Formation Post, students can push F1 key as many times as required, which will pop up a message on the simulator screen stating the task to be done. The student can navigate with no restrictions through the scenario by clicking on the mouse different buttons and choose his best viewpoint to carry out the shotcrete task. However, there are some viewpoints saved in the simulator already, which correspond to habitual position of experienced workers in shotcrete operations.

When the robotic arm collides with any wall, the TS alerts with a visual signal and takes the incident into account for evaluation. In order to avoid this type of failures, the simulator shows in every moment the distance from the hose to the nearest wall.

\section{Evaluation module}

The simulator counts on a subjective and objective evaluation.

Objective evaluation: It consists on automatic measurements and parameters that the simulator detects and do not require of the instructor. Following aspects can be evaluated: Milestone achievement; breakdowns management; execution time; mass of used and rejected concrete; shotcrete wall thickness and uniformity; aids usage (viewpoint change and F1 key push).

Subjective evaluation: The Instructor Post has to supervise all the Formation Posts. The instructor can record all the sessions and mark and comment at any moment including subjective criteria that later will comment with the correspondent pupil. This evaluation type is used upon second PBL characteristic, mentioned in Section 6.

\section{Validation of the Simulator as a Learning Tool}

A questionnaire was made to voluntary pupils to analyse their preliminary impressions. Student's assessment on the realism and the formative characteristics of the TS and interaction were studied. 
Table 3: Participants profile.

\begin{tabular}{|l|l|l|l|}
\hline Exercise type & Median & Mean & Deviation \\
\hline Participants age & 31.5 & 31.57 & 8.34 \\
\hline Previous familiarity with TS & 3 & 2.6 & 1.05 \\
\hline Previous familiarity with personal computers & 3 & 3.25 & 1.25 \\
\hline
\end{tabular}

Table 4: Questionnaire about the simulator.

\begin{tabular}{|l|l|l|l|}
\hline Exercise type & Median & Mean & Deviation \\
\hline P1- The easiness of the remote for the shotcrete spraying process & 4 & 3.75 & 0.74 \\
\hline P2- The easiness to concentrate on exercise and not on understanding the devices & 4 & 3.62 & 0.86 \\
\hline P3- How comfort is to use the TS to real shotcrete machine & 4 & 3.95 & 0.87 \\
\hline P4- Your motivation for doing simulator exercises & 4 & 3.95 & 0.84 \\
\hline P5- Entertainment of the usage of the TS & 4 & 4 & 0.81 \\
\hline P6- Assimilation of ideas with the simulator & 4 & 4.1 & 0.87 \\
\hline P7- The formative capacity of the TS & 4 & 3.9 & 0.7 \\
\hline
\end{tabular}

40 voluntary people took part, who were trained both with simulator and with real machine.

In Table 3 the profile of the participants is shown. Age of the pupils goes from 18 to 52 years and they evaluated their previous familiarity with the usage of TS with a Likert scale of 5 points, where $1=$ no familiarity and $5=$ very high familiarity. A positive correlation was found between familiarity with personal computers and TS. Following questionnaire was completed by SBF once they finished their formation, including hands-on practice. As can be observed on Table 4, participants appreciate formative qualities of the model and the realism. They felt really motivated along the training and they indicated a high degree of assimilation. And finally, the considered much more comfortable learning on the simulator rather than on hands-on practice.

\section{Discussion}

SBF has decided to incorporate a TS for the instruction on shotcrete machine usage. The simulator has a series of advantages against the real machine, such as a more efficient management of the resources, the simultaneous formation of various pupils in a more controlled and safer environment as well as get to have sides, the simulators offer a more exhaustive formation, as they permit recording exercises, repeating and plan very improbable situations in a hands-on practice.

The TS has been checked to be a good tool for skills learning. The simulator has been designed following education criteria and positive results on the questionnaire grant the tool as a good learning solution.

Shotcrete spraying is a complex process that requires cognitive, perceptual and motor skills. Besides, real environment is determined by low visibility and much noise. After analysing different alternatives, PBL was chosen to be the most efficient technique for this formation. PBL implementation requires of certain learning conditions, which constraint the design and development of the simulator and have been coped in following manner:

- High interactivity with the problem: The simulator works with a virtual world environment in which the user can control all the dofs of the machine through menus and a remote. Besides, the grade of realism is high (machine working process, shotcrete spraying physics and graphics, kind of exercises) to increase the pupils motivation and implication.

- Progressive learning: This aspect has been achieved thanks to scaffolding learning in which levels of the exercises are structured. This factor permits to emphasize specific aspects of the learning and crucial actions of the shotcrete management.

- Lack of instructions: The simulator counts on a series of characteristics that permit the user work without almost instructions. Some of them 
are the automatic advance in exercises, possibility of exploring the scenario or the robotic arm collision alert.

The positive correlation between with TS and personal computers was the expected result by the authors. Students with low familiarity should not worry about, as research works prove that this TS control can be acquired relatively in few weeks. The visual input in a simulator will probably be of lower quality compared to the visual input in a real life situation, but can be compensated in the simulator by adding appropriate information on a display. Moreover, in the research done by [15] proved that the shotcrete process in simulator and in reality was of high-fidelity.

If we take into account the critics done to TS in construction described in Section 4, this work advances in the state of the art, as it is a TS which was designed with the help of SBF mining school teachers and researchers. Moreover, results in Section 7 proof that TS is effective for learning according to shotcrete machine operators. This consensus among researchers, teachers and operators will lead to enhance the safety in this kind of works, learning and resources usage.

According to skilled workers, the most important differences between the tasks performed in the simulator and in real life were the unclear perception of distances and nozzle angles in the simulator in few occasions. It is harder to perceive the distance between the nozzle and the area to be sprayed in the simulator. This is a common problem of the simulators, which is related to the fact that a 3D world is represented in 2D, on a flat screen. Future work will go towards to integration in an immersive virtual reality, where the students will be able to explore the scenario with virtual reality glasses. This big step could lead to changes on the TS design, either software or hardware part. The questionnaire results show that the shotcrete modeling method was well accepted by the participants of the study. The ratings obtained are similar to the ones presented in other evaluation results $[9,31]$.

As future improvements, it should be considered the incorporation of all variables in the simulation that are variable in real life. For instance, the concrete flow, dosage, or air pressure at the nozzle and other kind of simulation approaches, such as the usage of MS Kinect [32].

\section{References}

1. Thomson JA, Tolmie AK, Foot HC, Sarvary P, Whelan $K M$, et al. (2005) Influence of virtual reality training on the roadside crossing judgments of child pedestrians. J Exp Psychol Appl 11: 175-186.

2. Sutherland LM, Middleton PF, Anthony A, Hamdorf J, Cregan P, et al. (2006) Surgical simulation: A systematic review. Ann Surg 243: 291-300.

3. Lucas J, Thabet W, Worlikar P (2008) A VR-based training program for conveyor belt safety. Journal of Information Technology in Construction 13: 381-407.

4. Sacks R, Perlman A, Barak R (2013) Construction safety training using immersive virtual reality. Construction Management and Economics 31.

5. Bernold LE (2005) Paradigm shift in construction education is vital for the future of our profession. Journal of Construction Engineering and Management 131: 533-539.

6. Goulding J, Nadim W, Petridis P, Alshawi M (2012) Construction industry offsite production: $A$ virtual reality interactive training environment prototype. Adv Eng Inform 26: 103-116.

7. de Vries B, Verhagen S, Jessurun AJ (2004) Building management simulation centre. Automation in Construction 13: 679-687.

8. Manca D, Brambilla S, Colombo S (2013) Bridging between virtual reality and accident simulation for training of process-industry operators. Advances in Engineering Software 55: 1-9.

9. Alm $\mathrm{H}$ (2015) The validity of a simulator for training of shotcrete operators. Division of Engineering Psychology, Luleå University of Technology, Sweden.

10.Valero A, Suescun A, Amundarain A (2009) A highly realistic training simulator for the tunneling jumbo sandivk dt1130-c data. In: Proceedings of the Hunstville Simulation Conference HSC, USA.

11.Girmscheid G, Moser S (2001) Fully automated shotcrete robot for rock support. Computer-Aided Civil and Infrastructure Engineering 16: 200-215.

12.Valero A, Velaz Y, de Dios C (2009b) Can skills improve a real training simulator of a tunnelling jumbo sandivk dt1130-c data? In: Proceedings of the Conference Skills, Spain.

13. Brazalez A, Ares J, Matey L (2006) Driving simulators: Past, present and future. Euromech Colloquium 476.

14. Brazalez A, Ares J (2006) Parallelization of dynamic terrain models based on discrete element method for earthmoving training simulators. In: First South-East European Conference on Computational Mechanics. 
15.Velez G, Matey L, Amundarain A, Suescun A, Marín J, et al. (2013) Modeling of shotcrete application for use in a real-time training simulator. ComputerAided Civil and Infrastructure Engineering 28: 465480.

16. Ruthenbeck GS, Reynolds KJ (2015) Virtual reality for medical training: The state-of-the-art. J Simulation 9: 16-26.

17.Jacobson D (2001) Presence revisited: Imagination, competence and activity in text-based virtual worlds. Cyberpsychol Behav 4: 653-673.

18. Mantovani F, Castelnuovo G (2003) The sense of presence in virtual training: Enhancing skills acquisition and transfer of knowledge through learning experience in virtual environments.

19.van der Zee DJ, Slomp J (2009) Simulation as a tool for gaming and training in operations management-a case study. Journal of Simulation 3: 17-28.

20.Finan E, Bismilla Z, Whyte H, Leblanc V, McNamara $P$ (2012) High fidelity simulator technology may not be superior to traditional low-fidelity equipment for neonatal resuscitation training. Journal of Perinatology 32: 287-292.

21.Salas E, Bowers CA, Rhodenizer L (2009) It is not how much you have but how you use it: Toward a rational use of simulation to support aviation training. Int J Aviat Psychol 8: 197-208.

22.Schrader C, Bastiaens TJ (2012) The influence of virtual presence: Effects on experienced cognitive load and learning outcomes in educational computer games. Computers in Human Behavior 28: 648-658.

23. Velez G (2013) Shotcrete model and simulation for real time training simulators, University of Navarra, Spain.
24.Jardon A, Victores JG, Martinez S, Balaguer C (2012) Experience acquisition simulator for operating microtuneling boring machines. Automation in Construction 23: 33-46.

25. Huang HM, Rauch U, Liaw SS (2010) Investigating learners' attitudes toward virtual reality learning environments: Based on a constructivist approach. Comput Educ 55: 1171-1182.

26.Lewis R, Stoney S, Wild M (1998) Motivation and interface design: Maximising learning opportunities. Journal of Computer Assisted Learning 14: 40-50.

27. Eskrootchi R, Oskrochi GR (2010) A study of the efficacy of project-based learning integrated with computer-based simulation-stella. Educational Technology \& Society 13: 236-245.

28. Hmelo-Silver CE (2004) Problem-based learning: What and how do students learn? Educational Psychology Review 16: 235-266.

29.Garcia-Robles R, del Rio FD, Vicente-Diaz S, LinaresBarranco A (2009) An e-learning standard approach for supporting $\mathrm{PBL}$ in computer engineering. IEEE Transactions on Education 52: 328-339.

30.Zumbach J, Reimann P (2003) Influence of feedback on distributed problem based learning. Springer Netherlands, Dordrecht 219-228.

31. Makanae K, Dawood N (2009) Development and evaluation of a tangible terrain representation system for high-way route planning. Computer-Aided Civil and Infrastructure Engineering 24: 225-235.

32. Montorio K, Hermano E, Martin C, Guieb A, Capuluan J, et al. (2019) Application of model based 3D hand tracking for mimicking robotic wrist with three degrees of freedom using Microsoft Kinect Xbox one. International Journal of Robotic Engineering 4. 